\section{Efficacy of leprosy vaccine}

SIR - C. L. Crawford ${ }^{1}$ begins by criticizing a statement in Nature by $\mathrm{K}$. S. Jayaraman $^{2}$ that the report by Convit et $a l$. in the Lancet earlier this year ${ }^{3}$ was the first demonstrated effect of $\mathrm{BCG}$ on leprosy in the New World because "this conclusion is drawn from a retrospective case-control study, which is different from the randomized double-blind trial...". Jayaraman's statement is correct. It is also true that the observation by Convit et al. was based on a case control analysis, but this does not invalidate their conclusions. Case control methods are now a well established method of estimating vaccine efficacy ${ }^{4,5}$, and thus the issue is whether the Venezuela study was properly conducted as we believe it was. Beyond this, more than 15 published studies, including cohort and case control studies, as well as randomized trials, have examined the effect of BCG on leprosy, and all have found significant protection ${ }^{6,7}$. Available evidence indicates that BCG vaccines are in fact more effective against leprosy than against tuberculosis 6,8 .

Crawford then expresses "surprise" at the omission of a placebo arm from the continuing leprosy vaccine trials in Venezuela and Malawi. The reasons are well known, and have been published ${ }^{3.9}$. In the Malawi study, the protective effect of BCG was established before the start of the trial ${ }^{10}$ and it was therefore judged unethical to include a placebo arm. In the Venezuela study, the protection conferred by BCG had not been established at the start of the trial, but the number of leprosy cases expected in the population was judged too small for a three-arm comparison. In evaluating a new vaccine, the question of public health importance is not the absolute efficacy of the new preparation but whether it can improve upon vaccines already being given to the population.

The points in the final paragraph of Crawford's letter are unclear to us, but may imply that declines in the incidence of leprosy and in particular of multibacillary disease, in some trial populations, have been a consequence of case finding and chemotherapy. There is no clear evidence for this, and, in any case, it is irrelevant to the issue of vaccine evaluation in a randomized trial. Declines in leprosy have been recorded in many populations in the absence of chemotherapy, and are expected as a consequence of improved socio-economic conditions $^{11}$. Available evidence indicates that the protection imparted by BCG against multibacillary disease is as great as that against paucibacillary disease $^{7,8}$. This is consistent in all published studies with the exception of the
Uganda trial (which included only a single multibacillary case $)^{12}$ and one small study described only in a letter ${ }^{13}$. We believe that there is now overwhelming evidence of the effectiveness and impact of BCG vaccination against leprosy. BCG has been delivered to populations mainly as a vaccine against tuberculosis, and over the past three decades some 3 billion doses have been administered globally. This is certainly one of the factors responsible for the decline in the incidence of leprosy observed in many countries in recent years ${ }^{7}$.

P. E. M. Fine

P. G. Smith

Department of Epidemiology and Population Sciences,

London School of Hygiene and Tropical Medicine,

Keppel Street,

London WC1E 7HT, UK

1. Crawford, C. L. Nature 359, 100 (1992).

2. Jayaraman, K. S. Nature 356, 373 (1992)

3. Convit, J. et al. Lancet 339, 446-450 (1992)

Smith, P. G. Tubercle 62, 23-35 (1982)

Orenstein, W. A., Bernier R. H., \& Hinman A. R. Epid.

Rev. 10, 212-241 (1988)

6. Fine, P. E. M. \& Rodrigues, L. C. Lancet I, 1016-1020 (1990)

. Fine, P. E. M. Int. J. Leprosy 60, 71-80 (1992).

8. Ponnighaus, J. M. Lancet 339, 636-639 (1992).

9. Fine, P. E. M. \& Ponnighaus J. M. Trans. R. Soc. trop. Med. Hyg. 82, 810-817 (1988)

10. Fine, P. E. M. et al. Lancet II, 499-502 (1986)

11. Fine P. E. M. Epid. Rev. 4, 161-188 (1982)

12. Stanley, S. J. J. Hyg. (Camb) 87, 233-240 (1981).

3. Abel L. et al. Lancet I, 1536 (1990).

\section{Travel restrictions}

SIR - During the Cold War, the communist regimes of East Europe sought to restrict freedom of travel for all their citizens, even those whom they allowed to travel abroad for science or business reasons. Thus in Poland scientists and businessmen were issued with special passes called service passes. The communist government urged Western nations not to issue visas unless a visa application was supported by a letter from a Polish authority (for example an embassy). The aim was to prevent Polish nationals from changing their route while already in the West. Most nations refused to treat such passes differently from normal Polish passes, but Spain, France and Italy signed consular agreements that they would request such letter before considering visa applications. As such a visa granted no extra privileges, its discriminatory nature was clear. Thus a Polish researcher elsewhere in Western Europe could pay a short visit to a French colleague only if he was behaving well and was prepared to wait three months or more for a permit from the Polish Embassy. The practice had nothing to do with the national interests of these Western nations since they surely would not be protected by Polish communists. On the contrary, I heard of scientists being blackmailed by the Polish authorities issuing such letters to collaborate in gathering intelligence against the collaborating Western nations.

The Cold War is over, the communist regimes vanished, Polish KGB-men charged with issuing such visa permits in Polish embassies are all unemployed, but Spanish diplomats still request their letters before issuing visas. The practice was always immoral. Now it is also anachronistic.

Alex Schwarzenberg-Czerny European Southern Observatory, Karl-Schwarzschild-Strasse 2, D-8046 Garching bei München, Germany

\section{British science}

SIR - Terence Kealey bemoans the imbalance in the origins of scientific effort between industrialized and developing nations ${ }^{1}$. In his desire for equality, his response in endorsing a slower growth of British science to redress the imbalance is injurious to the very people he seeks to help ${ }^{2}$. Beneficiaries are not limited to the geographical site of publication of the science. In the global village, both disease and scientific advances are quickly shared.

For example, the emergence of multidrug-resistant strains responsible for pneumonia, malaria and tuberculosis (the largest cause of death from a single infectious disease) is a worldwide concern $^{3}$. In applying the techniques of molecular genetics to target the pathogens causing tuberculosis, the recent work of Zhang et al. demonstrates its applicability to both North and South, despite the Anglo-French origin of the authors' collaborative efforts ${ }^{4}$.

This specific example is illustrative of the general proposition that, as in all trade, knowledge transfer is beneficial to both participants in the transaction. Knowledge transfer is less costly than autonomous knowledge development and frees resources, promoting longterm growth prospects and life quality in the recipient nation.

It would be cruel if, in the name of equality, a slower growth of science were somehow welcomed. That would truly be inequitable to potential beneficiaries, North and South.

Edward Krowitz

2415 North Dickerson Street,

Arlington, Virginia 22207, USA

1. Nature 358, $533(1992)$.
2. Nature 357, $272(1992)$.
3. Bloom, B. Nature $\mathbf{3 5 8}, 538$ (1992).
4. Zhang, Y. et al. Nature 358, 591-593 (1992) 